\title{
Human animal interface of SARS-CoV-2 (COVID-19) transmission: a critical appraisal of scientific evidence
}

\author{
Rubal Singla ${ }^{1} \cdot$ Abhishek Mishra $^{1} \cdot$ Rupa Joshi $^{1} \cdot$ Sonali Jha ${ }^{2} \cdot$ Amit Raj Sharma ${ }^{3} \cdot$ Sujata Upadhyay ${ }^{4} \cdot$ Phulen Sarma $^{1}$. \\ Ajay Prakash ${ }^{1} \cdot$ Bikash Medhi ${ }^{1}$
}

Received: 9 August 2020 / Accepted: 1 September 2020 / Published online: 14 September 2020

(C) Springer Nature B.V. 2020

\begin{abstract}
Coronaviruses are a large family of viruses that are known to infect both humans and animals. However, the evidence of intertransmission of coronavirus between humans and companion animals is still a debatable issue. There is substantial evidence that the virus outbreak is fueled by zoonotic transmission because this new virus belongs to the same family of viruses as SARS-CoV associated with civet cats, and MERS-CoV associated with dromedary camels. While the whole world is investigating the possibility about the transmission of this virus, the transmission among humans is established, but the interface between humans and animals is not much evident. Not only are the lives of human beings at risk, but there is an equal potential threat to the animal world. With multiple reports claiming about much possibility of transmission of COVID-19 from humans to animals, there has been a significant increase in the number of pets being abandoned by their owners. Additionally, the risk of reverse transmission of COVID-19 virus from companion pets like cats and dogs at home is yet another area of concern. The present article highlights different evidence of human-animal interface and necessitates the precautionary measures required to combat with the consequences of this interface. The Centers for Disease Control and Prevention (CDC) and the World Health Organization (WHO) have suggested various ways to promote awareness and corroborate practices for helping people as well as animals to stay secure and healthy.
\end{abstract}

Keywords COVID-19 $\cdot$ SARS-CoV-2 $\cdot$ Pets $\cdot$ Zoonotic

\section{Impacts:}

- With the emergence of SARS-CoV-2/COVID-19 around the globe, not only humans but their companion animals are also found to be at comparative risk.

- Various experimental studies from different countries provided evidence of the possible role of the human animal interface in COVID19 transmission.

- The World Health Organization (WHO) has advised to take general precautionary measures to prevent cross species COVID-19 transmission. Moreover, the Ministry of Environment, Forest and climate change has suggested regular examination of abnormal animal behavior in zoos. Protective measures are required to save the companion animals from virus transmission.

Bikash Medhi

drbikashus@yahoo.com

Rubal Singla

singlarubal1995@gmail.com

Abhishek Mishra

pharmapgiabhishek@gmail.com

Rupa Joshi

rupajoshiaiims@gmail.com

Sonali Jha

sonali1763@gmail.com

\author{
Amit Raj Sharma \\ amitrajsharma1992@gmail.com \\ Sujata Upadhyay \\ tupshi20@yahoo.co.in \\ Phulen Sarma \\ phulen10@gmail.com \\ Ajay Prakash \\ ajayprakashpgi@gmail.com
}

Extended author information available on the last page of the article 


\section{Introduction}

The recent outbreak of SARS-CoV-2 has caused a serious global threat. The speed with which this virus is spreading all over the world has crossed the rate at which the understanding of the disease and its effects is evolving amongst scientists, public health officials, and other members of the global health community. While the pandemic continues, scientists are looking at tracing the species from which the infection may have originated (Guo et al. 2020). In the light of the evidence depicting its first circulation in bats before transmitting via intermediate host to humans, a new question on whether this virus has the capability of transfer from human to animal is trending. Various new cases have come forward in revealing the transmission of this novel virus from infected humans to animals (Ng and Hiscox 2020). Moreover, the risk of reverse transmission from companion animals to humans can also increase the risk of COVID-19 infection. Although there is limited evidence of transmission of the virus among pets, yet the likelihood of its transmission to companion humans has also been discussed by various scientists and public health officials. The goal of this article is to review the possible transmission of COVID-19 in animal species in the context of positive animal corona cases worldwide and reach a possible conclusion. Moreover, precautionary measures to protect pets and other animals from the virus have also been discussed. This review is built on a narrow range of data available till date and general instructions for preventing and monitoring the consequences of the human animal interface. There is an urgent need to promote awareness and corroborate practices for helping people as well as animals to stay secure and healthy. Furthermore, it provides a quick insight into the suspected SARS-CoV-2 reservoirs and introduces some safety measures for humans as well as companion animals to control the spread of COVID-19.

\section{Corona viruses and history of their origin}

Coronaviruses $(\mathrm{CoV})$ are a group of viruses belonging to the family of Coronaviridae. These families of viruses infect both humans and vertebrate animals (Ng and Hiscox 2020). Four types of corona viruses, namely, HKUI, NL63, OC43, and 229E, also known to cause respiratory diseases (Saif et al. 2019), while SARS-CoV, MERS-CoV, and SARS-CoV-2 can be responsible for causing severe pulmonary injury and respiratory distress which may cause fatality in humans.

The two major events in the past resulted in severe diseases due to the transmission of viruses of beta $(\beta)$ genera from animals to humans (Guarner 2020). In 2002-2003, the first event occurred in China into Guangdong province when a beta coronavirus which originated in bats moved to human via palm civet cats which acted as their intermediate host
(Martina et al. 2003). A decade later, in 2012, another coronavirus named as the Middle East Respiratory Syndrome coronavirus, designated as MERS-CoV was originated in Saudi Arabia and its transmission took place from bats with dromedary camels being the intermediate host (Qian et al. 2013). It was reported to infect about 2494 people with 858 fatalities. Recently, at the end of the year 2019, Wuhan, a major business centre in China, experienced an emergence of a new corona virus, i.e., SARS-CoV-2 (COVID-19) which is also described to be a subtype of the $\beta$ subgroup of coronaviruses (Xu et al. 2020a). SARS-CoV-2 has drastically spread over more than 200 countries and territories around the world, infecting around 2 million people across the world. Not only does this virus attack on various organs of the body including the respiratory system, gastrointestinal system, liver, but as well as invades the central nervous system, and causes illness to both humans and various animals such as bats, cattle, birds, mice etc. (Salata et al. 2019).

\section{The host and primary reservoirs of SARS-CoV-2}

The findings of the genetic sequence testing reveal that the new SARS-CoV-2 has about $80 \%$ similarity with SARS$\mathrm{CoV}$. This data was released by the Military Medical Research Institute of Nanjing Military Region. Another report by Shi et al. described the SARS-CoV-2 to share $96.2 \%$ similarity with the SARS-CoV coronavirus that originated from Rhinolophus affini (bats) (Xu et al. 2020b). This clearly illustrates that the new emerging virus may have also originated from bats. However, the intermediate host for this virus is elusive, some reports have stated snakes or minks to be the intermediate hosts. Recently, a group of researchers from the Agricultural university of South China analyzed over one thousand metagenomic samples and observed that about $70 \%$ pangolins out of more than 1000 metagenomic samples were found to be positive for the coronavirus ( $\mathrm{Lu}$ et al. 2020). Also, there was $99 \%$ similarity of the genetic sequence between the pangolins and the present infectious human strain (Zhang and Holmes 2020). Based on these evidence, there is a high probability of the pangolins to be one of the intermediate host of COVID-19 (Zhang et al. 2020a; Lam et al. 2020).

\section{Zoonotic origins of SARS-CoV-2}

Bats have been identified to be an important reservoir host for an array of coronaviruses. In the past several years, frequent sampling has recognized various bat corona viruses. The data from the genomic comparisons exhibited viruses from bat to have a major correlation with SARS-CoV-2 (Zhang and Holmes 2020). Another study by Yadav et al. tested bat 
samples from seven different states of India and found the rectal swab test of eight samples of Rousettus spp. and Pteropus spp. to be positive for RdRp gene. Additionally, in the same study, the results of the next generation sequencing revealed that the four sequence regions of Rousettus spp. had about approximately $94.3 \%$ similarity to the previously found coronaviruses in bat (Yadav et al. 2020). Since there is a general ecological separation between bats and humans, it is possible that some mammalian species act as an 'intermediate' or 'amplifying' host. It is likely that the recently emerged coronavirus acquired the much) needed mutations within these hosts for human transmission (Ahmad et al. 2020). Civets and camels acted as the intermediate host for SARS and MERS, respectively, white camels are thought to be the true reservoir hosts from MERS (de Wit et al. 2016). The recently discovered SARS-CoV-2 virus is found to be closely related to the Malayan pangolins (Manis javanica). These pangolins were imported illegally from the Guangdong and Guangxi provinces of Southern China (Lake 2020). The Guangdong pangolin viruses are explicitly related to the SARS-CoV-2 in the receptor binding domain and containing all six key mutations that are believed to shape the virus for binding to the Angiotensin Converting Enzyme (ACE) 2 receptor and manifesting about $97 \%$ similarity of the amino acid sequence (Hasan et al. 2020). However, the Guangdong pangolin viruses showed high divergence in the remaining genome. The various evidence from the past clearly suggest that the evolution of the virus in both reservoir and intermediate animal hosts needs to be explored to better evaluate the emergence of SARS-CoV-2 in humans. However, studies revealing the acquirement of key mutations by the virus during abstruse transmission in humans prior to its detection should not be ignored.

\section{Mechanism of entry and transmission of SARS-CoV-2}

A group of researchers suggested that pangolins and bats act as a carrier for SARS-CoV-2 due to similarity in their genetic makeup. Inspite of there being a reasonable correlation of SARS-CoV-2 with MERS-CoV and SARS-CoV, there are some remarkable differences between these viruses. SARSCoV-2 gains entry into human cells using spike proteins followed by a series of complex processes (Shereen et al. 2020) (Fig. 1). Once SARS-CoV enters inside the host body, it targets cells through an endosomal pathway. The initial attachment of the virion to cells occurs via $\mathrm{S}$ protein binding to the ACE-2 receptors (Ji et al. 2020). The conformational change in $\mathrm{S}$ protein assists the fusion of the viral envelope with the cell membrane, thereby liberating the infectious RNA in the host cell. This RNA is then translated by viral replicase polyproteins PP1a and PP1ab, followed by its cleavage by the viral proteinases into smaller products forming a full length negative-strand template for the genomic RNA (Song et al. 2019). During translation, viral protein particles are formed. Viral protein and genome RNA are assembled in a step-wise manner by virion in the endoplasmic reticulum and golgi. The new virion is then released from the cell through exocytosis (Zhang et al. 2020b). Now, the new virions have the ability to infect other body organs. These virions can contaminate other humans via close contact in communities. Some evidence also suggested that it can also affect pets like cats and dogs.

\section{Do coronaviruses infect animals?}

Coronaviruses are generally found in various domestic and wild animal species including cattles, horses, ferrets, bats, dogs, and others (Ng and Hiscox 2020). Current evidence suggest that the major transmission route is from human to human. Although not common, coronaviruses can also be transmitted from animals to humans. The outbreak of the major coronaviruses in the past in humans suggested that bats act as reservoirs for these viruses that crossed the species barrier and infected humans as well as other domestic and wild mammals (Malik et al. 2020). There were also studies which reported the fact that palm civet cats (SARS) and dromedary camels (MERS) acted as the intermediate host (Abdullahi et al. 2020). The origins of COVID-19 virus are also believed to be from animal source. At present, there are numerous research programs dedicated to finding the potential source as well as species involved in the emergence of this pandemic. The genomic sequence data reveals $80 \%$ similarity between the SARS-CoV-2 and the previous human coronavirus (SARS-CoV), establishing its close relation to the Rhinolophus bat (Horseshoe bat) population (Fig. 2). There is also a possibility of the involvement of an intermediate host for transmission to humans. Health officials have found the first SARS-CoV-2 infections to be linked to the live animal market in China (Liu and Saif 2020). However, till date, there are not enough scientific documental evidence to explain the original route of transmission from animal to human sources.

\section{Are other species such as mosquitoes, houseflies responsible for the transmission of virus to humans?}

Till date, there is no evidence that COVID-19 or any other similar corona viruses such as SARS or MERS are spread through mosquitoes or ticks because the virus needs to replicate inside the mosquito if it has to pass to a person through the mosquito (Eslami and Jalili 2020). 


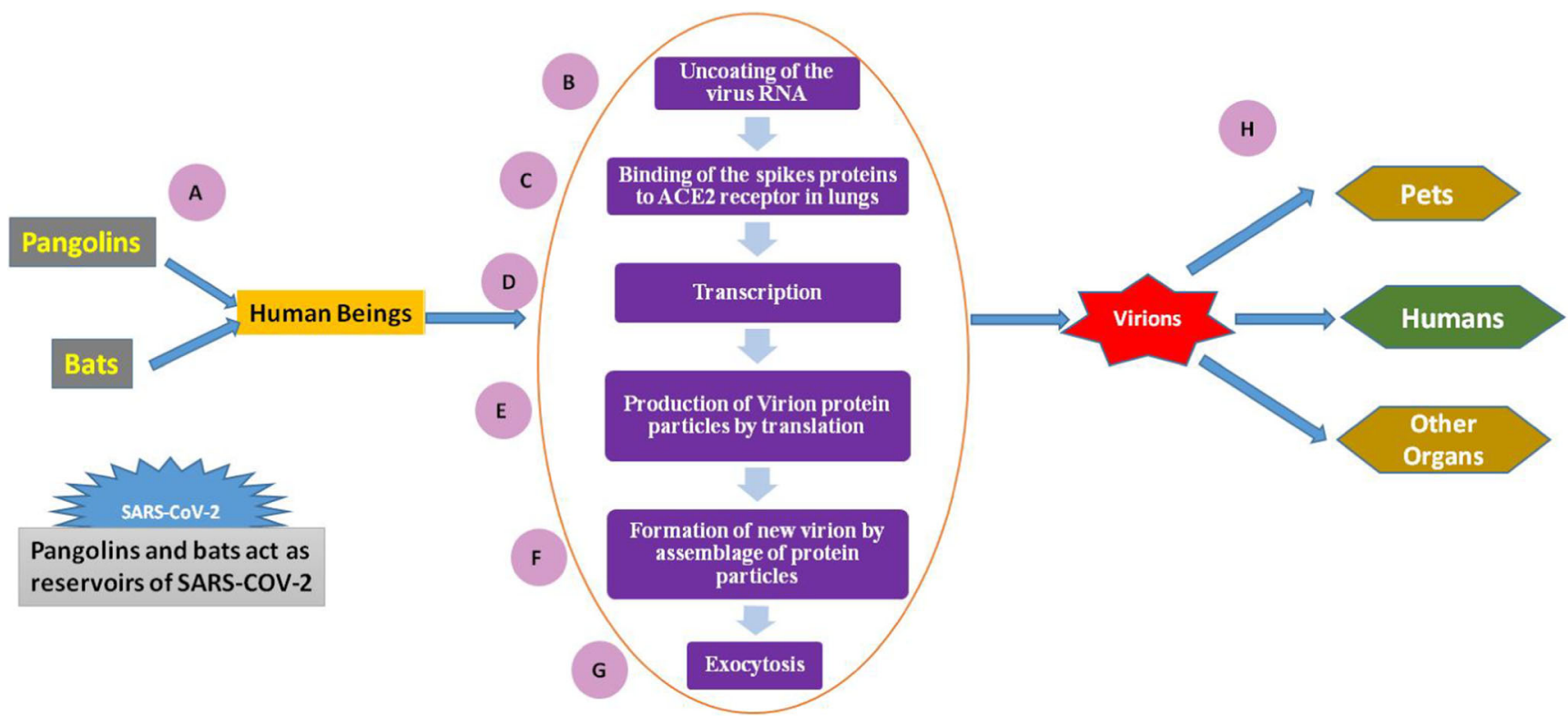

Fig. 1 The mechanism of entry and transmission of SAR-CoV-2 in human host. (A) Pangolins and bats act as reservoirs of SARS-CoV-2. (B) Binding of the spikes proteins to ACE2 receptor of human lungs. (C) Uncoating of the virus RNA. (D) Transcription (E) Production of Virion

\section{In-vivo experimental studies of SARS-CoV-2 transmission between animals}

\section{Study on ferrets (China)}

To check the susceptibility of SARS-CoV-2 in ferret a two virus samples, F13-E and $\mathrm{CTan}-\mathrm{H}$ that were previously protein particles by translation. (F) Formation of new virion by assemblage of protein particles. $(\mathrm{G})$ Exocytosis (H) Released virion can infect (animals \& other humans)

isolated from environmental samples in the Huanan Seafood market in Wuhan and human patients respectively, were inoculated intranasal in a pair of ferrets $\left(10^{5} \mathrm{pfu}\right)$. The qPCR and virus titration test conducted on the various isolated organs of the ferrets on day 4 post inoculation detected infectious virus in the nasal turbinate, soft palate and tonsils of ferrets indicating the possible replication of the virus in the upper respiratory
Fig. 2 A. Evidence suggested that bats and pangolins are the animal reservoir for SARS-CoV2 virus; B. SARS-CoV-2 patients transmit virus to their pets by activities like touching, feeding and cuddling etc.; $\mathrm{C}$. Infected pets can also infect the other healthy person by having close contact

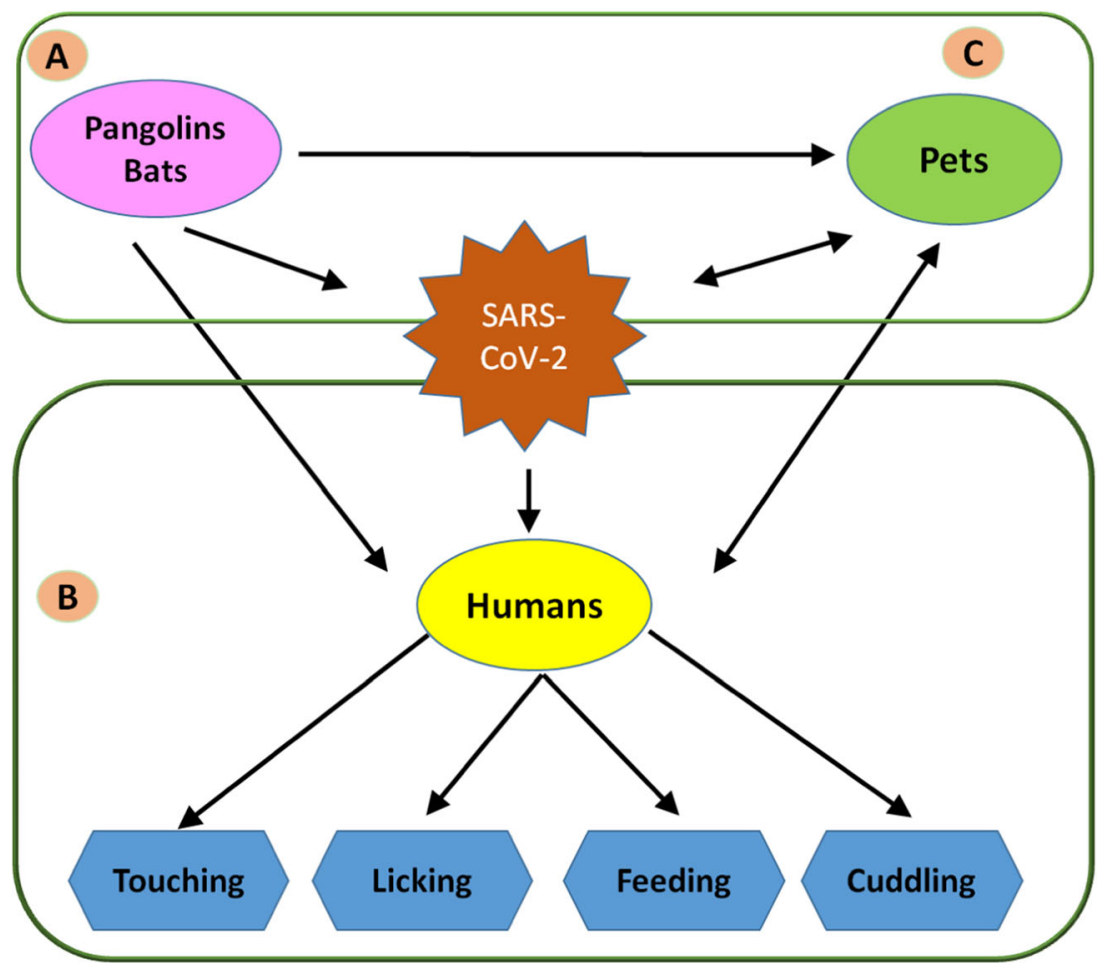


tract of the ferrets while no infection was found in other organs such as trachea, lung, heart, spleen, kidneys, pancreas, small intestine, brain and liver of the ferrets (Kim et al. 2020). Further, when a group of three animals intranasal inoculated with $10^{5} \mathrm{pfu}$ of F13-E and CTan-H placed in three separate cages with uninfected ferrets, the nasal washes of six ferrets were detected with viral RNA after day 2, 4, 6 and 8 of inoculation. However, the rectal swabs of the ferrets were noted to have lower copy numbers of the infectious virus RNA. Three ferrets also had a loss of appetite and developed fever on days 10 and 12 (Stittelaar et al. 2016). To check whether the symptoms were caused due to the virus, the tissues and organs of the two ferrets were euthanized at p.i 13. Low copy number of the virus RNA was detected in the turbinate of the CTan-H inoculated ferret. Furthermore, the ELISA results revealed the presence of antibodies against SARS-CoV-2 in all the ferrets (El-Duah et al. 2019). The investigation on the lungs of the ferrets to check the viral replication in these organs was done by intratracheal inoculation of eight ferrets with $10^{5} \mathrm{pfu}$ of CTan-H. The animals were euthanized on p.i days $2,4,8$, and 14 to check the viral RNA in various tissues and organs. The results indicated that the SARS-CoV-2 replicates upto 8 days in the upper respiratory tract of the ferrets without causing any severe disease.

\section{Experiment on ferrets (South Korea)}

Young-ll Kim et al. checked the transmission of SARSCoV-2 in ferrets in an experimental setting (van den Brand et al. 2008). The study was conducted for a period of 12 days. Two ferrets were intranasally inoculated with an isolated strain $\left(10^{5.5}\right.$ TCID $_{50}$ of NMC-nCoV02) of a COVID-19 positive South Korea patient. After 2 days post inoculation, two naive ferrets per group were either housed together with infected ferrets (direct contact) or were kept in cages having a permeable partition to separate them from the inoculated ferrets (indirect contact). The results of this experiment revealed a rise in the body temperature of all the direct contact ferrets to about $39{ }^{\circ} \mathrm{C}$ on average, accompanied by reduced activity. On the contrary, none of the indirect contact ferrets acquired elevated body temperatures. Thus, we can infer that the efficient transmission of SARS-CoV-2 clinical symptoms requires direct contact with the infected animals (Shi et al. 2020). Further, the replication of the virus amongst all groups of ferrets was investigated by collecting saliva, nasal washes, blood, urine and fecal samples consecutively for 12 days. The viral RNA copies were calculated using quantitative RT-PCR. These viral RNA copies were then compared with the number of standard control copies. The results of the viral RNA showed the maximum viral RNA in the nasal washes at pi days 4 and 8 . The saliva as well as the fecal matter of the direct contact ferrets was detected with viral RNA on p.i day 8 . For the indirect contact group, only two out of six ferrets had viral RNA in nasal washes as well as fecal specimens from pi day 4 . In addition, the copy number of the viral RNA in the indirect contact ferrets was lower than in the direct contact ferrets. The nasal turbinate and lung tissues had the highest number of viral RNA copies, 4 dpi. Moreover, there was the presence of a small amount of viral RNA in the kidney and intestine of ferrets after day 4 of inoculation. The virus was also tracked down in the lungs, kidney, trachea, nasal turbinate, and intestine at $8 \mathrm{dpi}$. Additionally, the immunohistochemistry and histopathological examination of the various tissues of ferrets revealed that cells in the nasal turbinate, lung, and trachea of the infected ferrets were positive for SARS-CoV-and acute bronchiolitis by NMC-nCoV02 infection (van den Brand et al. 2008). This study results stipulate ferret to have high susceptibility for the SARS-CoV-2 and this infectious virus sheds by multiple routes of body discharge specimens such as urine and faeces of the infected ferrets which serve as a potential source of viral transmission to close contact.

\section{Study on cats}

To investigate the replication of the SARS-CoV-2 virus in cats, an in-vivo study was performed in which five cats were inoculated with $10^{5} \mathrm{pfu}$ (intranasal) of CTan-H. Amongst them, two of the infected cats were sacrificed on pi 6 and viral RNA was found in the various isolated organs of the cat after euthanizing them on p.i day 6 (Mallapaty 2020). The virus was detected in the nasal turbinates, tonsils, soft palates and trachea. However, no infection was found in the lung samples of the animal. The other three sub adult cats were placed separately with three uninfected cats in different cages (Kim et al. 2020). The fecal samples of all virus inoculated sub adult cats were detected with viral RNA on p.i day 5 while only one exposed cat showed viral RNA in the feces. After the cats were euthanized on p.i day 11, viral RNA was also found in the tonsils and soft palate of the infected cat, while in the nasal turbinate, soft palate, tonsils and trachea of the exposed cat. Thus, it was clear that the transmission through respiratory droplets had occurred. Furthermore, the results of the ELISA and neutralization assay revealed that antibodies of SARS-CoV-2 were found in all the three pre inoculated cats and one exposed cat (El-Duah et al. 2019). Similar experiments were performed with juvenile cats and the histopathological examination revealed massive lesions in the nasal, mucosal and lungs of the cats. Based on these studies, it has been found that SARS-CoV-2 can be replicated in both adult and young cats and the mode of transmission between cats was via respiratory droplets. 


\section{Experiment on dogs}

The study examined the transmission and replication of SARS-CoV-2 in dogs. Five beagles of age 3 months were inoculated intranasal with $10^{5} \mathrm{pfu}$ of $\mathrm{CTan}-\mathrm{H}$ and were placed along with two naive dogs. The rectal swabs and oropharyngeal swabs were collected until p.i day 14 . The viral RNA was detected only in two inoculated dogs on pi 2 and in rectal swabs of one dog on pi 6 . The viral RNA positive dog did not show infection in any organs or tissues after it was euthanized from p.i 4. The results of the ELISA were seronegative for all except for two virus inoculated dogs which were found to be seroconverted on p.i day 14. Thus, it is clear from the experiment that dogs are less susceptible to SARS-CoV-2 infection (Shi et al. 2020).

\section{Experiments on pigs, chickens and ducks}

A similar set of experiments were performed in pigs, chicken and ducks to investigate the virus susceptibility in these animals. The results from the experiment clearly stated that neither the inoculated animals nor the naive contacted animals were detected with viral RNA in the swab test. Similar results were observed in the ELISA experiment where all the animals were seronegative for SARS-CoV-2 on post inoculation day 14. Based on the results of this experiment, we can infer that pigs, chickens, ducks are not susceptible to this virus (Shi et al. 2020).

\section{Can humans transmit COVID-19 virus to animals?}

As SARS-CoV-2 is widely disseminating in the human population, it is likely that animals in close contact with humans can get infected as well (Almendros 2020). Various studies are being carried out to understand the vulnerability of different animal species to the virus and in better assess the infection dynamics in these susceptible animals. Till date, some animals such as dog, cats, and tiger are found to be infected with the virus following close contact with infected humans (Goumenou et al. 2020). The latency period for SARS-CoV-2 is almost similar in both humans and animals. On average, it ranges from 3 to 7 days to upto 14 days. Surprisingly, the symptoms in animals are not certain, some develop dry cough, etc. (Fig. 3). This human animal interface may even remain asymptomatic and can sometimes be contagious and act as silent sources of transmission $(\mathrm{Ng}$ and Hiscox 2020). However, there is no current evidence suggesting the possibility of animals infected by humans in spreading the virus.
Evidence in favor of human-animal interface

\section{Human-to-canine transmission}

\section{Pomeranian dog}

Hong Kong's Agriculture, Fisheries, and Conservation Department (AFCD) reported on February 27, 2020, that the nasal and oral cavity samples of a 17-year-old Pomeranian dog were diagnosed as "weak positive" according to the results of the RT-PCR (real-time reversetranscriptase polymerase chain reaction). The dog was already quarantined as the owner of the dog had been earlier diagnosed with COVID-19 (Almendros 2020). The dog did not show any symptoms of illness. However, the results of the fecal sample and the rectal swab were negative. The reports of RT-PCR testing on the nasal cavity repeated on February 28, March 2, 5, and 9 were again found to be weak positive, indicating the presence of a minute amount of SARS-CoV-2 RNA in these samples. Moreover, the results of the genome data sequencing of the dog and its close human contacts completed on March 12 suggested a high similarity between the viral sequences. The virus neutralizing antibody test completed on March 12 was negative. The RT-PCR conducted on March 12 and 13 consecutively were reported to be negative and thus the Pomeranian was released on the following day. However, the dog died three days later and unfortunately the owner of the dog did not allow a postmortem examination (Mallapaty 2020). The death was possibly due to various co-morbidities and the age of the dog and was unlikely to be associated to COVID-19. The scientist of Hong Kong University believed that there was a possibility of the transmission of the virus from the infected owner to the dog considering the persistence of the positive results from the Pomeranian's samples.

\section{German shepherd dog}

The second possible human-to-dog transmission was reported on March 19 when a two year old German shepherd dog living in Pok Fu Lam was tested positive for COVID-19. As seen earlier, the 30 years old owner of the dog was also infected with the virus. However, the dog did not show any symptoms of respiratory discomfort during its quarantine period (Sit et al. 2020). The Agriculture, Fisheries and Conservation Department reported that the results of RT-PCR on the oral and nasal samples of the dog came out to be positive. Until 25th March, 17 dogs and 8 cats of the owners with confirmed cases or people in contact with confirmed cases were tested and monitored. However, only 2 dogs mentioned earlier were positive for SARS-CoV-2. 
Fig. 3 Comparison of various aspects of COVID-19 between humans and animals

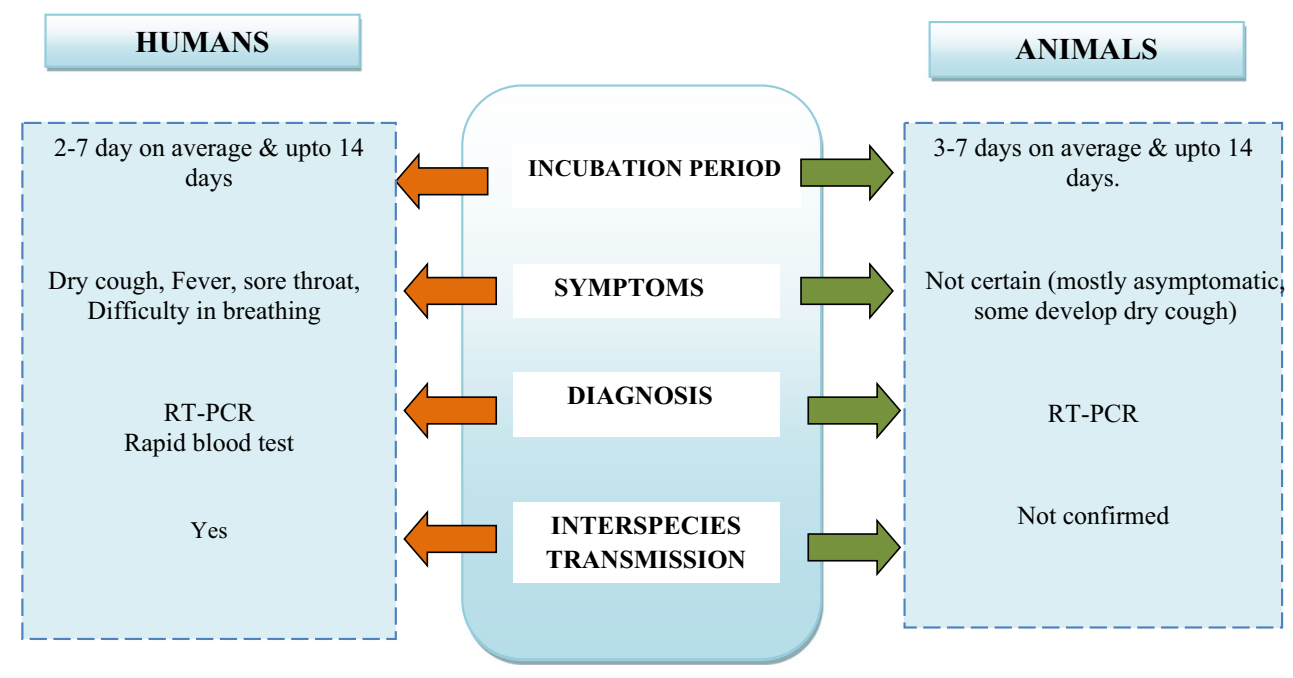

\section{Cases of human - cat (FELINE) transmission}

\section{Cat in Belgium}

The Federal Agency for Safety of the Food Chain (FASFC) was informed on March 18,2020 by the Faculty of Veterinary Medicine at the University of Liege that a cat in Belgium was found to be positive for the coronavirus (Mallapaty 2020). The reports of PCR (high throughput sequencing) detected the viral RNA of SARS-CoV-2 in the faeces and vomit of the cat. The cat was likely to pick up the virus from its owner who after travelling to northern Italy fell sick with SARSCoV-2. The cat started to show symptoms of illness a week later and had signs of respiratory and digestive dysfunction. The cat was quarantined and recovered after nine days. Currently, we do not have any evidence regarding the potential other conditions which may lead to respiratory and gastrointestinal signs. Once the cat is released from quarantine, the research will be carried out for the SARS-CoV-2 antibodies in the blood test, which would provide the true proof of the infection. The virologist named Steven Van Gucht made it clear that this case was about human-to-animal transmission and not vice-versa. However, he also stated that this was a rare case and the possible risk of animal to human transmission is very small.

\section{Pet cat in Hong Kong}

A pet cat in Hong Kong was tested positive with COVID- 19 on March 31, 2020 after it was quarantined on March 30 after its owner, a women of the Shek Pai Wan Estate, Aberdeen was infected with the corona virus. The samples collected from the nose, mouth, and rectum of the cat were tested positive for the virus. However, the cat did not show any signs of the disease. It is believed to be the second cat in the world to be infected with this virus (Pet cat in Hong Kong 2020).
Tiger in zoo- New York

A female Malayan tiger name Nadia from the Bronx Zoo in New York City was found to be having respiratory illness and thus tested positive for COVID-19 on April 72,020. The test results were confirmed by the National Veterinary Services Laboratory at Lowa. The Samples of the four-year-old female tiger along with six other animals who had developed dry cough and started showing indications on the 27th of March were taken and are believed to be infected with COVID-19. However, till date only the results of Nadia are confirmed to be positive (Gollakner and Capua 2020). This animal is believed to have acquired the infection from an asymptomatic zoo-keeper after which she started to display a loss of appetite and dry cough. This case was the first case to be documented of COVID-19 infection in US animals as well as tigers all over the world. These findings raise new questions about the transmission of the virus in animals.

\section{Minks in Netherlands}

Minks are commonly farmed for their fur in Netherlands. However, two of the mink farms (one in the province North Brabant, South Netherlands observed a increase in the mink mortality in mid April 2020. Some these minks displayed signs of respiratory signs (mostly nasal discharge). All the minks in these farms were separately caged and there was no connection of workers, transport between the two farms. The necropsied samples from the dead minks tested positive for SARS-CoV-2. Histological findings revealed severe diffuse pneumonia with hyperaemia, alveolar damage as well as air containing alveolar lumina in lungs of the dead minks. The qPCR analysis detected the presence of viral RNA in the liver and intestines of some animals. Also, the throat swabs of 
all the necropsied animals showed the presence of viral RNA. On further investigation of the farm owners and workers, four members on one of the two farms have had respiratory disease symptoms in the start of april but did not get checked for SARS-CoV-2 infection. Additionally, one of the people who stayed in the farm was later detected with SARS-CoV-2 by the end of april. Moreover, one of the workers of farm two was hospitalized on March 31 due to COVID-19. These results further confirm the possibility of transmission of the virus between humans and animals (here, minks). Inhalable dust samples were collected three times between April 28 and May 16 at different locations in the mink house. Viral Ran was detected in two of the three samples from farm one and one sample in farm two. Also, 24 stray cats around the farms were sampled for the SARS-CoV-2 and results revealed the presence of antibodies against SARS-CoV-2 in seven cats and viral RNA in one cat.

The mink outbreaks are "spillover" from the human pandemic - a zoonosis in reverse. The most likely explanation for the widespread infection on the mink farms is the possibility of the introduction of the virus by the humans to the minks. The minks were caged separately with non-permeable partition between the cages, precluding the direct contact as a mode of transmission amongst the minks. Thus, the indirect transmission may have occurred through the food or the bedding material, infected droplets generated by the infected animals or by the contaminated fecal matter. Sequence analysis of mink-derived viruses pointed at humans as the probable source of the initial infection and demonstrated transmission between minks. Furthermore, the presence of viral RNA in inhalable dust collected from the farms indicated a possible exposure of workers to virus excreted by minks. Similar cases were found in around nine other farms in Netherlands but there possible connection with the first two cases has not been detected yet. (Oreshkova et al. 2020).

\section{How to stay healthy around animals}

It is not yet comprehensive to comment whether animals, including livestock, pets, and wild life pose any risk of COVID19 infection. However, adequate precautions should be taken while dealing with pets or any other animals such as washing hands properly after any contact with the animals, their food, or animal waste (Marconato and Finotello 2020). Also, utmost care should be taken to clean up the pets properly and to follow a good pet hygiene as they may otherwise contain germs which may make humans sick. There should be regular visits to the veterinarians or assistance from them if the need arises about pet health.

\section{How to protect pets if you are sick?}

Although there are very few reports on whether SARS-CoV-2 can be transmitted from humans to animals, it is recommended that confirmed as well as suspected individuals with COVID-19 to have restricted contact with pets or other animals until more information about the transmission is available. Continual exposure to humans hosting the corona virus would sooner or later possibly cause major threats to these animals to extinction. Thus, limited exposure and frequent contact would considerably reduce the threat and in turn ensure the safety of both the pet and the owner (Decaro et al. 2020). It is also suggested that if there is no other member of the family to take care of the pet while the owner is infected, proper hygiene should be maintained around the pet. The owner or the infected person should avoid physical contact such as kissing, licking, snuggling, or sharing food with the pet and wash his hands before and after interaction with them. Safe hygiene practice needs to be ensured while handling and caring for the pets and special precautions should be taken when in close proximity with the animal, such as wearing a mask. When handling and caring for the animals, they should maintain good hygiene practices and wear a mask. Moreover, the infected person should not have common drinking glasses, utensils, towels, bedding with pets at home (Huang et al. 2020).

\section{Keeping pets safe}

To keep the pets safe during this pandemic, it is advisable to have an emergency kit prepared in advance containing sufficient food and medications for at least two weeks (Aitken 2020). Since there are not enough evidence that pets can spread the virus to other animals or humans, it is not recommended to remove pets from the homes of people where COVID-19 is confirmed or suspected in any member of the household. In case if the pets are not able to be taken care properly, veterinarians are there to support the good health of the pets.

\section{Can pets spread COVID-19 to humans?}

We need to understand that there is a difference between the pets contracting the virus and a pet spreading the virus to humans. The research experts said that the likelihood of humans contracting COVID-19 from their pets is low. Also according to the CDC reports, there is no evidence for transmission of the novel corona virus from companion animals to humans. The major route of transmission appears to be from person-to- person by contact with saliva or other bodily secretions through cough or sneeze (COVID-19: Coronavirus and 
Pets FAQ 2020). Transmission through contaminated surfaces and objects remains the secondary route of transmission. However, non-porous materials such as door knobs have higher capacity to transmit the virus as compared to nonporous surfaces. Since pet furs belongs to the category of non-porous surfaces and are likely to trap and absorb the virus, it is harder to contract the virus onto them through simple touch. On the contrary, there are chances of dissemination of the virus to humans from the body fluids of pet animals. Since pet dogs and cats are always in close proximity to their owners, there are chances of transmission through kissing, licking, and playing with the pets (Fig. 2). Moreover, researchers have found that most of the cats and ferrets that were infected with the virus are asymptomatic, showing no signs of coughing, sneezing, weight loss, or raised body temperature (Halfmann et al. 2020). Thus, it is likely that the owners of the infected pet animals would not have noticed any change in their pets. In view of the fact that SARS-CoV-2 virus was also detected in the feces of animals experimentally inoculated with the human virus titre, there are chances that the virus contaminated faecal matter and urine of pet animals can transmit the virus to humans. It has been advised by all healthcare agencies that COVID-19 confirmed positive cases must avoid contact with companion animals (Can your pet get COVID-19 2020). Social distancing (at least $6 \mathrm{ft}$ ) should be maintained even with pets or other companion animals outside the household.

With the increasing reports of transmission of COVID-19 from infected humans to pets (like cats and dogs) and tigers and lions, there is an urgent need for public health officials to identify and investigate the possibility of virus transmission from pets to humans. At present, people should emphasize on preventing the possible transmission of SARS-CoV-2 on to their pets. In accordance with the data from various experimental reports, cats infected with the virus having no appreciable clinical signs can act as a silent transmitter of COVID19 infection to humans (CDC 2020). Recently, the CDC has issued the following guidelines for pet owners to keep themselves safe and healthy.

- Always wash your hands after contact with the pets or their belongings such as their cages, beds, food and food utensils, animal waste, etc.

- Do not allow children and elderly people to handle or be around the animals.

- The family members suffering from diseases like diabetes, hypertension, and other immunity compromised diseases should not come into contact with their pets.

- The pets and their food items should be kept away from the kitchen.

- $\quad$ Rough playing with the pets should be avoided to prevent any scratches and bites. Moreover, avoid kissing, snuggling, or holding the animals close to the face.
Immediate medical care should be given in case of any type of scratches or bites. Furthermore, pets should also be monitored for clinical symptoms or any unusual change in their behavior.

\section{Are there any precautions to be taken with live animals or animal products?}

The World Health Organization (WHO) has advised people to take general precautions while visiting live animal markets, animal product markets, or wet markets because there is still uncertainty about the exact origin of this virus (Zhonghua 2020). Also, it is recommended to wash hands regularly with soap and potable water after any contact with animals or their products as well as avoid touching eyes, nose or mouth after contact with sick animals or spoiled animal products. Adequate precautions should be taken to avoid any contact with animal waste or fluids on the soil or any other surfaces. Any contact with stray animals such as dogs, cats, birds, rodents living in the streets to be completely restricted. Additionally, even though no research based evidence has proven the spread of this virus due to intake of seafood, chicken, or mutton, still the intake of any raw or uncooked milk, meat, or any kind of animal organs should be avoided as per the general good food safety practices (Wang et al. 2020).

\section{Precautionary measures for zoos}

Since the report of the New York zoo tiger tested positive for COVID-19, the Ministry of Environment, Forest and climate change has advised zoos to remain at high alert and regularly observe animals for any abnormal behaviors or symptoms. The advisory has ordered that the care takers of zoo animals should wear proper personal protective equipment and maintain limited contact with animals while feeding them. In addition, the sick animals are advised to be quarantined and all zoo personnel should strictly follow the safety and disinfection protocol issued by the government (COVID-19: Alipore zoo 2020). Proper screening, testing, and surveillance of the diagnostic samples should be done whenever required. Along with this, an advisory has been issued to all the chief Wildlife wardens of states and union territories by the Ministry of environment which includes the following instructions:

- Proper regulatory measures should be taken by all the National parks, Sanctuaries, and Tiger reserves to prevent the spread of SARS-CoV-2 from humans to animals.

- There should be reduction in the human and wildlife interface.

- Movement of people to the National parks and sanctuaries should be curtailed. 
- Management of the current situation with the help of task force to be undertaken as soon as possible.

- A significant enhancement in the mapping, tracing, monitoring, and surveillance of the system in coordination with various departments.

- Emergency services for the treatment of animals, if required, should be undertaken.

- Proper reporting to the nodal officer should be done in any type of noticed cases.

- Other possible steps to be followed to prohibit the spread of the virus.

\section{Conclusion}

The comparison of the human version of the coronavirus to previously isolated strains from animals was possible only due to the availability of the complete genetic sequencing of the SARS-CoV-2 (Kannan et al. 2020). Various evidence suggested that bats are the primary reservoirs of the novel corona virus and thus the major source of infection to humans. Since the SARS-CoV-2 genomic sequence in humans and pangolin has shown significant relatedness, these animals are suspected to be the intermediate host for this infection (Xu et al. 2020c). However, the routes of direct or indirect zoonotic transmission are still to be unveiled. Thus, comprehensive studies on how an animal virus crossed the species boundaries to infect human species are required to discover the precise routes of transmission. Besides, the veterinary community has also been trying to identify the risks to animals and possible zoonotic transmission. Various cases of human to animal transmission have also come up indicating the risk of the virus to domestic animals or pets (Oreshkova et al. 2020). The literature reveals that cats and ferrets are susceptible to COVID-19 infection. These infected animals could efficiently spread the virus to naive animals directly in contact with them. Additionally, the ACE2 receptors in a few animal species are found to be similar to the human ACE2 receptors, thus further stipulating the possibility of the human-animal interface. These findings also indicate that domestic cats and ferrets can be an effective animal model for screening candidate vaccines and drugs against SARS-CoV-2 (Hasan et al. 2020). Although it is still not certain that humans can transmit COVID-19 to their pets or other animals, it is recommended to follow some preventive measures and basic animal hygiene. Moreover, we cannot believe that just if the pets can be infected with SARS-CoV-2, they can also spread it. At this time, there is no literature proving the transmission of the virus from the infected pets to their owners. A lot of research is needed to determine the role of the animals in the spread of the virus. However, social distancing needs to be maintained with animals as with humans. By doing so, we can reduce the human as well as zoonotic transmission of SARS-CoV-2. Furthermore, some experimental studies and serosurveillance studies in different animal species should be continued to reach an effective conclusion and prevent further zoonotic events.

Data availability Data sharing is not applicable to this article as no new data were created or analyzed in this study.

\section{Compliance with ethical standards}

Conflict of interest None of the authors declared any potential conflict of interest.

Ethical statement Ethical statement is not applicable as this is a review article.

\section{References}

Abdullahi IN, Emeribe AU, Mustapha JO, Fasogbon SA, Ofor IB, Opeyemi IS, Obi-George C, Sunday AO, Nwofe J (2020) SARSCoV-2, SARS-CoV, and MERS-COV: a comparative overview. Le infezioni in medicina $28: 166-173$

Ahmad T, et al. (2020) COVID-19: Zoonotic aspects. Travel Medicine and Infectious Disease. Published online : 24 February 2020. https:// doi.org/10.1016/j.tmaid.2020.101607

Aitken MM (2020) Ensuring animal welfare during Covid-19 pandemic. The Veterinary record 186:389

Almendros A (2020) Can companion animals become infected with Covid-19? Vet Rec 186:388-389

Can your pet get COVID-19? (https://www.indiatoday.in) Accessed 19 May 2020

CDC: About Pets \& People. ( https://www.cdc.gov). Accessed 18 May 2020

COVID-19: Alipore zoo takes measures to prevent coronavirus spread (https://www.outlookindia.com). Accessed on 19 May 2020

COVID-19: Coronavirus \& Pets FAQ. (https://www.oregonvma.org) Accessed 18 May 2020

de Wit E, van Doremalen N, Falzarano D, Munster VJ (2016) SARS and MERS: recent insights into emerging coronaviruses. Nat Rev Microbiol 14:523-534

Decaro N, Martella V, Saif LJ, Buonavoglia C (2020) COVID-19 from veterinary medicine and one health perspectives: what animal coronaviruses have taught us. Res Vet Sci 131:21-23

El-Duah P et al (2019) Development of a whole-virus ELISA for serological evaluation of domestic livestock as possible hosts of human coronavirus NL63. Viruses 11:43

Eslami H, Jalili M (2020) The role of environmental factors to transmission of SARS-CoV-2 (COVID-19). AMB Express 10:92

Gollakner R, Capua I (2020) Is COVID-19 the first pandemic that evolves into a panzootic? Vet Ital 56:7-8

Goumenou M, Spandidos DA, Tsatsakis A. (2020) Possibility of transmission through dogs being a contributing factor to the extreme Covid-19 outbreak in North Italy. Molecular Medicine Reports. Published online: 23 March 2020. https://doi.org/10.3892/mmr. 2020.11037 
Guarner J (2020) Three emerging coronaviruses in two decades: the story of SARS, MERS, and now COVID-19. Am J Clin Pathol 153:420 421

Guo Y-R et al (2020) The origin, transmission and clinical therapies on coronavirus disease 2019 (COVID-19) outbreak-an update on the status. Military Medical Research 7:1-10

Halfmann PJ, et al. (2020) Transmission of SARS-CoV-2 in Domestic Cats. The New England Journal of Medicine. Published on: 13 May 2020. https://doi.org/10.1056/NEJMc2013400

Hasan A, et al. (2020) A review on the cleavage priming of the spike protein on coronavirus by angiotensin-converting enzyme- 2 and furin. Journal of Biomolecular Structure and Dynamics 2020; 113. Published online: 22 April 2020. https://doi.org/10.1080/ 07391102.2020 .1754293

Huang Q, Zhan X, Zeng X-T. (2020) COVID-19 pandemic: stop panic abandonment of household pets. Journal of Travel Medicine. Published online: 9 April 2020. https://doi.org/10.1093/jtm/taaa046

Ji X, et al. (2020) TWIRLS, an automated topic-wise inference method based on massive literature, suggests a possible mechanism via ACE2 for the pathological changes in the human host after coronavirus infection. BioRxiv 2020; Published online: 1 March,2020. https://doi.org/10.1101/2020.02.27.967588

Kannan S, Shaik Syed Ali P, Sheeza A, Hemalatha K (2020) COVID-19 (novel coronavirus 2019) - recent trends. Eur Rev Med Pharmacol Sci 24:2006-2011

Kim YI, et al. (2020) Infection and rapid transmission of SARS-CoV-2 in Ferrets. Cell Host Microbe. Published online: 6 April 2020. https:// doi.org/10.1016/j.chom.2020.03.023

Lake MA (2020) What we know so far: COVID-19 current clinical knowledge and research. Clinical Medicine 20:124-127

Lam TT, et al. (2020) Identifying SARS-CoV-2 related coronaviruses in Malayan pangolins. Nature. Published online: 26 March 2020. https://doi.org/10.1038/s41586-020-2169-0

Liu SL, Saif L (2020) Emerging viruses without borders: the Wuhan coronavirus. Viruses 12:130

Lu R, Zhao X, Li J, Niu P, Yang B, Wu H, Wang W, Song H, Huang B, Zhu N, Bi Y, Ma X, Zhan F, Wang L, Hu T, Zhou H, Hu Z, Zhou W, Zhao L, Chen J, Meng Y, Wang J, Lin Y, Yuan J, Xie Z, Ma J, Liu WJ, Wang D, Xu W, Holmes EC, Gao GF, Wu G, Chen W, Shi W, Tan W (2020) Genomic characterisation and epidemiology of 2019 novel coronavirus: implications for virus origins and receptor binding. Lancet 395:565-574

Malik YS, et al. (2020) Emerging coronavirus disease (COVID-19), a pandemic public health emergency with animal linkages: Current status update. Published online: 23 March 2020. https://doi.org/10. 20944/preprints202003.0343.v1

Mallapaty S (2020) Coronavirus can infect cats - dogs, not so much. Nature .Published online: 1 April,2020. https://doi.org/10.1038/ d41586-020-00984-8

Marconato L, Finotello R (2020) Veterinary oncologists adapting to COVID-19 pandemic. Veterinary and comparative oncology. Published online: 30 March 2020. https://doi.org/10.1111/vco. 12593

Martina BEE, Haagmans BL, Kuiken T, Fouchier RAM, Rimmelzwaan GF, van Amerongen G, Peiris JSM, Lim W, Osterhaus ADME (2003) SARS virus infection of cats and ferrets. Nature 425:915 934

Ng LFP, Hiscox JA (2020) Coronaviruses in animals and humans. Br Med J 368:m634

Oreshkova $\mathrm{N}$ et al (2020) SARS-CoV-2 infection in farmed minks, the Netherlands, April and May 2020. https://doi.org/10.2807/15607917.ES.2020.25.23.2001005

Pet cat in Hong Kong tests positive for Covid-19 after owner becomes infected.( https://www.todayonline.com) Accessed 5 May 2020
Qian Z, Dominguez SR, Holmes KV (2013) Role of the spike glycoprotein of human Middle East respiratory syndrome coronavirus (MERS-CoV) in virus entry and syncytia formation. PLoS One 8: $5-10$

Saif LJ et al (2019) Coronaviruses. Diseases of swine:488-523

Salata C et al (2019) Coronaviruses: a paradigm of new emerging zoonotic diseases. Pathogens and Disease 77:6

Shereen MA, Khan S, Kazmi A, Bashir N, Siddique R (2020) COVID-19 infection: origin, transmission, and characteristics of human coronaviruses. J Adv Res 24:91-98

Shi J, et al. (2020) Susceptibility of ferrets, cats, dogs, and other domesticated animals to SARS-coronavirus 2. Science. Published on 8 April 2020. https://doi.org/10.1126/science.abb7015

Sit THC, et al. (2020) Infection of dogs with SARS-CoV-2. Nature. Published online: 14 May 2020. https://doi.org/10.1038/s41586020-2334-5

Song Z, Xu Y, Bao L, Zhang L, Yu P, Qu Y, Zhu H, Zhao W, Han Y, Qin C (2019) From SARS to MERS, thrusting coronaviruses into the spotlight. Viruses 11:59-63

Stittelaar KJ, de Waal L, van Amerongen G, Veldhuis Kroeze E, Fraaij P, van Baalen C, van Kampen J, van der Vries E, Osterhaus A, de Swart R (2016) Ferrets as a novel animal model for studying human respiratory syncytial virus infections in immunocompetent and immunocompromised hosts. Viruses 8:168

van den Brand JMA, Haagmans BL, Leijten L, van Riel D, Martina BEE, Osterhaus ADME, Kuiken T (2008) Pathology of experimental SARS coronavirus infection in cats and ferrets. Vet Pathol 45: $551-562$

Wang Q, Zhang Y, Wu L, Niu S, Song C, Zhang Z, Lu G, Qiao C, Hu Y, Yuen KY, Wang Q, Zhou H, Yan J, Qi J (2020) Structural and functional basis of SARS-CoV-2 entry by using human ACE2. Cell 181:894-904

$\mathrm{Xu}$ J et al (2020a) Systematic comparison of two animal-to-human transmitted human coronaviruses: SARS-CoV-2 and SARS-CoV. Viruses 59:12-22

Xu J, Zhao S, Teng T, Abdalla AE, Zhu W, Xie L, Wang Y, Guo X (2020b) Systematic comparison of two animal-to-human transmitted human coronaviruses: SARS-CoV-2 and SARS-CoV. Viruses $12: 244$

Xu Z, Shi L, Wang Y, Zhang J, Huang L, Zhang C, Liu S, Zhao P, Liu H, Zhu L, Tai Y, Bai C, Gao T, Song J, Xia P, Dong J, Zhao J, Wang FS (2020c) Pathological findings of COVID-19 associated with acute respiratory distress syndrome. Lancet Respir Med 8:420-422

Yadav PD, Shete-Aich A, Nyayanit DA, Pardeshi P, Majumdar T, Balasubramanian R, Ullas PT, Mohandas S, Dighe H, Sawant P, Patil S, Patil D, Gokhale MD, Mathapati B, Sudeep AB, Baradkar S, Kumar A, Kharde R, Salve M, Joshi Y, Gupta N, Mourya DT (2020) Detection of coronaviruses in Pteropus \& Rousettus species of bats from different states of India. Indian J Med Res 151:226-235

Zhang YZ, Holmes EC (2020) A genomic perspective on the origin and emergence of SARS-CoV-2. Cell 181:223-227

Zhang T, Wu Q, Zhang Z (2020a) Probable pangolin origin of SARS-CoV2 associated with the COVID-19 outbreak. Curr Biol 30:1346-1351

Zhang H, Penninger JM, Li Y, Zhong N, Slutsky AS (2020b) Angiotensin-converting enzyme 2 (ACE2) as a SARS-CoV-2 receptor: molecular mechanisms and potential therapeutic target. Intensive Care Med 46:586-590

Zhonghua liu xing bing xue za zh The epidemiological characteristics of an outbreak of 2019 novel coronavirus diseases (COVID-19) in China. Epidemiology Working Group for NCIP Epidemic Response, Chinese Center for Disease Control and Prevention. 2020; 41: 145-151

Publisher's Note Springer Nature remains neutral with regard to jurisdictional claims in published maps and institutional affiliations. 


\section{Affiliations}

Rubal Singla ${ }^{1} \cdot$ Abhishek Mishra $^{1} \cdot$ Rupa Joshi $^{1} \cdot$ Sonali Jha ${ }^{2} \cdot$ Amit Raj Sharma ${ }^{3} \cdot$ Sujata Upadhyay ${ }^{4} \cdot$ Phulen Sarma $^{1}$. Ajay Prakash ${ }^{1} \cdot$ Bikash Medhi $^{1}$

1 Department of Pharmacology, Post Graduate Institute of Medical Education \& Research (PGIMER), Chandigarh, India

2 Department of Biotechnology, National Institute of Pharmaceutical Education and Research, (NIPER) S.A.S. Nagar, Mohali, India
3 Department of Neurology, Post Graduate Institute of Medical Education \& Research (PGIMER), Chandigarh, India

4 Department of Physiology, Dr. Harvansh Singh Institute of Dental Science, Panjab University, Chandigarh, India 